\title{
Susut Tegangan pada Penghantar ACCC di Saluran Transmisi 150 kV di PT. PLN (Persero) Unit Pelayanan Transmisi Pekanbaru
}

\author{
Wellington Octary ${ }^{1}$, Hamzah Eteruddin ${ }^{2}$, Abrar Tanjung ${ }^{3}$ \\ 1,2,3 Program Studi Teknik Elektro, Fakultas Teknik, Universitas Lancang Kuning \\ Jl. Yos Sudarso km. 8 Rumbai, Pekanbaru, Telp. (0761) 52324 \\ Email: wellington@wnpepc.com, hamzah@unilak.ac.id, abrar@unilak.ac.id
}

\begin{abstract}
ABSTRAK
Sistem jaringan transmisi memegang peranan penting untuk operasional dalam penyaluran sistem tenaga listrik, khususnya pada saluran transmisi $150 \mathrm{kV}$. Pada tahun 2013 terjadi penggantian penghantar tipe ACSR ke ACCC disaluran transmisi $150 \mathrm{kV}$ Garuda Sakti-Balai Pungut dikarenakan pembangkit listrik di Riau sudah semakin banyak dan penyaluran listrik ditiap penghantar akan memasok arus yang lebih besar, pada saat penghantar diberi arus yang besar,ACCC mampu menghantarkan Arus dua kali lipat dibandingkan denganACSR.Single line diagram Unit Pelayanan Transmisi Pekanbaru, data saluran GI Garuda Sakti-Balai Pungut data penghantar dan beban adalah data-data yang diperlukan untuk perhitungan pada penghantar konduktor tipe ACCC pada saluran transmisi $150 \mathrm{kV}$ GI Garuda Sakti-Balai Pungut .Hasil dari perhitungan tersebut akan diperoleh suatu kesimpulan banyak susut tegangan rugi-rugi daya dan andongan dari penghantar ACCC sebesar 5,098 kV kerugian daya sebesar 479,187 kW dan nilai andongan sebesar $6,950 \mathrm{~m}$, dan akan dibandingkan dengan penghantar lama yaitu tipe ACSR sebesar 7,517 kV kerugian daya sebesar 828,863 dan nilai andongan sebesar 9,010 m disaluran transmisi 150 kV di PT. PLN Persero Unit Pelayanan Transmisi Pekanbaru.
\end{abstract}

Kata Kunci: Saluran Transmisi, Konduktor, Susut Tegangan, Andongan

\section{ABSTRACT}

Power transmission network system plays an important role in distributing power, especially in $150 \mathrm{kV}$ power transmission lines. In 2013, the was a change in term of conductor type in in $150 \mathrm{kV}$ transmission lines of Garuda Sakti - Balai Pungut, from ACSR to ACCC, because of the growing number of power plants in Riau and power distribution in every conductor supplying higher current, when given higher current, ACCC conductor is capable of transmitting power twice the ACSR conductor. The single line diagram of UPT Pekanbaru, data from power station (GI) Garuda Sakti - Balai Pungut, conductor data and load data are all data necessary for the study and calculation on ACCC conductor. The result shows that the amount of voltage drop power losses of ACCC conductor is $5.098 \mathrm{kV}$, while the power loss is 479,187 with the sagging value is $6.950 \mathrm{~m}$, compared to the old conductor, the ACSR type, with the voltage drop of $7.517 \mathrm{kV}$, power loss of $828.863 \mathrm{~kW}$, and the sagging value of $9.010 \mathrm{~m}$, all measured in $150 \mathrm{kV}$ power transmission lines of PT. PLN Persero UPT Pekanbaru.

Keywords: Power Transmission Network, Conductor, Voltage Drop, Sagging

\section{PENDAHULUAN}

Penyaluran energi listrik dari pembangkit ke pusat beban. Konduktor merupakan bagian yang sangat penting dalam penyaluran energi listrik dari pusat pembangkit ke konsumen. Oleh karena itu, konduktor yang digunakan harus memiliki kemampuan hantar arus yang besar dan mempunyai karakteristik temperatur yang tinggi. Transmisi bertegangan tinggi 
menjadi pilihan utama penyaluran daya listrik, hal ini dilakukan untuk menekan biaya pembangunan jaringan listrik dengan kapasitas daya yang sangat besar. Transmisi bertegangan tinggi memiliki batas penyaluran daya sedangkan kebutuhan energi listrik masyarakat semakin hari semakin bertambah.

Konduktor tembaga memiliki kelebihan dibanding kawat penghantar aluminium karena konduktivitas dan kuat tariknya lebih tinggi. Kelemahannya, untuk besar tahanan yang sama, tembaga lebih berat daripada aluminium dan juga lebih mahal. Oleh karena itu konduktor aluminium telah menggantikan kedudukan konduktor tembaga [1].

Saat ini terdapat konduktor jenis baru yaitu Alumunium Conductor Composite Core (ACCC). Konduktor ini merupakan jenis konduktor yang digunakan sebagai penghantar pada sebagian sistem Saluran Udara Tegangan Tinggi (SUTT) Riau pada jaringan transmisi dari Gardu Induk (GI) Garuda Sakti sampai GI Duri.

\section{Sistem Tenaga Listrik}

Menurut jenisnya, arus terbagi atas 2 yaitu arus bolak balik (AC atau Alternating Current) dan arus searah (DC atau Direct Current). Dalam sistem arus bolak balik, untuk menaikkan ataupun menurunkan tegangan dapat dilakukan dengan menggunakn transformator. Pada saat ini, umumnya saluran transmisi menggunakan arus bolak balik (AC). Pada sistem arus bolak balik ada sistem satu fasa dan sistem 3 fasa. Sistem tiga fasa memiliki kelebihan dari pada sistem satu fasa, karena [1]:

a. Daya yang disalurkan lebih besar.

b. Harga sesaatnya (Instantaneous Value) konstan.

c. Magnet putarnya mudah dihilangkan.

Ada 2 kategori saluran transmisi yaitu saluran udara (Overhead Line) dan saluran kabel bawah tanah (Underground Cable). Kedua cara penyaluran tersebut mempunyai untung dan rugi masing-masing, dibandingkan dengan saluran udara, saluran bawah tanah tidak terpengaruh oleh cuaca buruk, angin topan, hujan, petir dan lain sebagainya. Saluran bawah tanah lebih estetis karena tidak mengganggu pandangan, karena alasan terakhir ini saluran kabel bawah tanah lebih disukai terutama untuk daerah padat penduduknya. Namun biaya yang dibutuhkan untuk pembangunnanya jauh lebih mahal dibandingkan dengan saluran udara dan perbaikannya lebih sulit bila terjadi gangguan [2].

\section{Transmisi Tenaga Listrik}

Untuk daya yang sama, efisiensi penyaluran akan meningkat karena rugi-rugi transmisi menurun. Namun peningkatan tegangan transmisi berarti juga menaikkan biaya pada isolasi, biaya peralatan dan gardu induk. Oleh karena itu, pemilihan tegangan pada saluran transmisi dilakukan dengan memperhitungkan daya yang disalurkan, jumlah rangkaian, jarak penyaluran, keandalan (Reability), biaya peralatan untuk tegangan tertentu, serta tegangan yang ada dan yang akan direncanakan [1].

Meskipun tidak jelas menyebutkan keperluannya sebagai tegangan transmisi, di indonesia pemerintah telah menyelaraskan deretan tegangan tinggi sebagai berikut ini [2], [3]:

1. Tegangan nominal sistem $(\mathrm{kV}) ; 30-66-$ $110-150-220-220-380-500$

2. Tegangan tertinggi untuk perlengkapan $(\mathrm{kV}) ; 36-72,5-170-245-420-525$

\section{Komponen Utama Saluran Udara}

Komponen-komponen utama dari saluran udara adalah sebagai berikut :

a. Menara transmisi serta pondasinya.

b. Isolator

c. Kawat penghantar (Conductor)

d. Kawat tanah (Ground Wires)

\section{Menara Transmisi}

Menara atau tiang transmisi adalah suatu bangunan penopang saluran transmisi, yang bisa berupa menara baja, tiang baja, tiang beton bertulang, dan tiang kayu. Tiang-tiang baja, beton, atau kayu pada umumnya digunakan pada saluran dengan tegangan kerja relatif rendah (dibawah $70 \mathrm{kV}$ ) sedangkan untuk saluran tranmisi tegangan tinggi atau ekstra tinggi digunakan menara baja, seperti pada Gambar 1. Menara baja dibagi sesuai fungsinya, yaitu menara dukung, menara sudut, menara ujung, menara pencabangan dan menara transposisi [1]. 

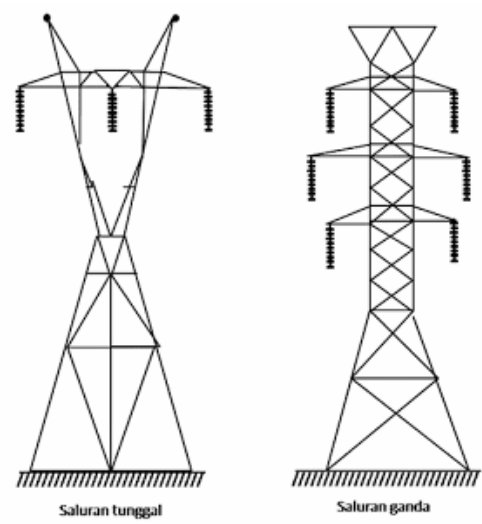

Gambar 1. Menara Transmisi saluran tunggal dan ganda

\section{Isolator}

Jenis isolator yang digunakan pada saluran transmisi adalah jenis porselin atau gelas. Menurut penggunaan dan konstruksinya dikenal tiga jenis isolator yaitu isolator pasak, isolator jenis pos-saluran dan isolator gantung. Seperti pada Gambar 2 berikut [1]:

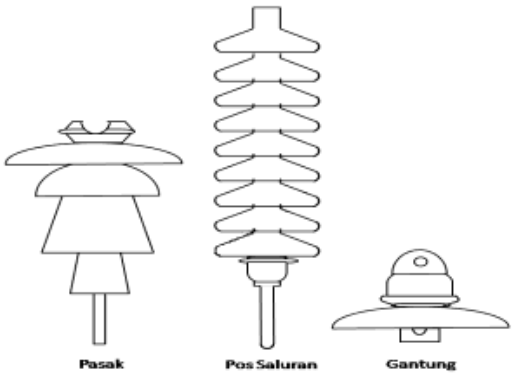

Gambar 2. Isolator pasak, isolator pos-saluran, dan gantung

Isolator jenis pasak dan pos-saluran digunakan pada transmisi dengan tegangan kerja relatif rendah (kurang 22-33 kV), sedangkan isolator gantung dapat digandeng menjadi rentengan isolator yang jumlahnya dapat disesuaikan dengan kebutuhan [4].

\section{Konduktor Penghantar}

Penghantar alumnium paduan mempunyai kuat tarik (Tensile strength) yang lebih tinggi dibandingkan dengan penghantar aluminium biasa. Awalnya jenis kawat penghantar yang biasa digunakan pada saluran transmisi adalah tembaga dengan konduktivitas $100 \%$ (CU 100\%), tembaga dengan konduktivitas $97,5 \% \quad(\mathrm{CU} \quad 97,5 \%$ ) atau aluminium dengan konduktivitas 61\% (Al 61\%) [2], [5]. Umumnya Saluran Udara Tegangan Tinggi (SUTT) ataupun Saluran Udara Ekstra
Tegangan tinggi (SUTET) menggunakan konduktor pilin (Stranded), guna mempermudah dalam penanganannya. Berikut beberapa jenis konduktor saluran udara; AllAluminium Conductor (AAC), All-AluminiumAlloy Conductor (AAAC), AluminiumConductor Steel Reinforced (ACSR), Aluminium Conductor Alloy Reinforced (ACAR), Aluminium Conductor Composite Core (ACCC), High Voltage Composite Reinforced Conductor (HVCRC) [4], [6], [7]. Beberapa penelitian telah dilakukan pada saluran transmisi maupun saluran distribusi [8][10].

Impedansi $(Z)$ terdiri dari resistansi $(R)$ dan reaktansi (X), impedansi merupakan parameter utama pada saluran transmisi. Impedansi merupakan suatu besaran komplek yang terdiri dari besaran ril (resistansi) dan besaran imaginer (reaktansi). Penulisan impedansi komplek yang menunjukkan besaran ril dan imajiner disebut dengan penulisan rectangular, impedansi saluran suatu sistem tenaga listrik dari resistansi dan reaktansi saluran diformulasikan sebagai persamaan [11]

$$
Z=R+j X
$$

Keterangan :

$$
\begin{aligned}
& \mathrm{Z}=\text { Impedansi Saluran }(\mathrm{Ohm}) \\
& \mathrm{R}=\text { Tahanan Saluran }(\mathrm{Ohm}) \\
& \mathrm{X}=\text { Reaktansi Saluran }(\mathrm{Ohm})
\end{aligned}
$$

Nilai tahanan pada saluran ditentukan oleh resistivitas konduktor $(\rho)$, panjang saluran $(l)$, dan luas penampang konduktor $(A)$. Dapat ditunjukkan seperti persamaan dibawah ini [2]:

$$
R=\rho \frac{l}{A}
$$

Umumnya, yang digunakan adalah konduktor pilin (stranded conductors) maka sebagai faktor koreksi akibat pengaruh dari pilin tersebut, panjang konduktor dikalikan dengan 1,02 [2]. Sementara tahanan konduktor juga dipengaruhi oleh perubahan temperatur, dalam batas temperatur $10{ }^{\circ} \mathrm{C}$ sampai $100{ }^{\circ} \mathrm{C}$, untuk Aluminium dan tembaga digunakan persamaan berikut [2].

$$
\begin{aligned}
& R_{t_{2}}=R_{T_{1}}\left[1+\alpha_{t_{2}}\left(t_{2}-t_{1}\right)\right] \\
& \alpha_{t_{1}}=\frac{1}{T_{0}+t_{1}}
\end{aligned}
$$


SainETIn (Jurnal Sain, Energi, Teknologi \& Industri), Vol. 5 No. 1, Desember 2020, pp. 1 - 7

ISSN 2548-6888 print, ISSN 2548-9445 online

Keterangan :

$R_{t 2}=$ Tahanan pada temperatur $t_{2}$

$R_{t 1}=$ Tahanan pada temperatur $t_{1}$

$\alpha_{t 1}=$ Koefisien temperatur dari tahanan pada temperatur $t_{1}{ }^{\circ} \mathrm{C}$

$T_{0}=$ temperatur dimana tahanan konduktor akan menjadi nol,

Dengan menggunakan persamaan linier yakan diperoleh nilai $T_{0}$ merupakan temperatur absolut $\left(-273^{\circ} \mathrm{K}\right)$. Untuk tembaga $(\mathrm{Cu})$ yang memiliki konduktivitas $100 \%$, maka koefisien temperatur dari tahanan pada suhu $20^{\circ} \mathrm{C}$ adalah [2]:

$$
\begin{aligned}
& \alpha_{20}=0,00393 \\
& T_{0}=\frac{1}{0,00393}-20=234,5^{\circ} \mathrm{C}
\end{aligned}
$$

\section{METODE PENELITIAN}

Data yang ada pada artikel ini diperoleh dari PT. PLN (Persero) Unit Pelayanan Transmisi (UPT) Pekanbaru Gardu Induk Garuda Sakti dan Gardu Induk Balai Pungut. Tahapan penelitian (flowchart) adalah sebagaimana terlihat pada Gambar 3.

\section{Metode Pengumpulan Data}

Mekanisme pengumpulan data dalam penyelesaian penelitian berupa data primer diperoleh langsung dari lapangan pada salah satu menara transmisi dan gardu induk. Juga dengan melakukan diskusi terbuka terhadap pegawai maupun teknisi terkait agar lebih memahami data data yang diperoleh. Sementara Data sekunder diperoleh melalui pengajuan permohonan data resmi ke PT. PLN (persero), dan pengumpulan referensi dari artikel ilmiah, serta katalog pendukung dari konduktor Aluminium Conductor Composite Core (ACCC) [7], [12].

\section{Susut Tegangan Pada Saluran Transmisi}

Susut tegangan $(\Delta \mathrm{V})$ merupakan selisih tegangan kirim $\left(\mathrm{V}_{\mathrm{K}}\right)$ dan tegangan terima $\left(\mathrm{V}_{\mathrm{T}}\right)$. Susut tegangan pada saluran tenaga listrik secara umum berbanding lurus dengan panjang saluran dan beban serta berbanding terbalik dengan luas penampang penghantar. Atau besar arus yang mengalir pada masing-masing konduktor dikalikan dengan impedansinya.

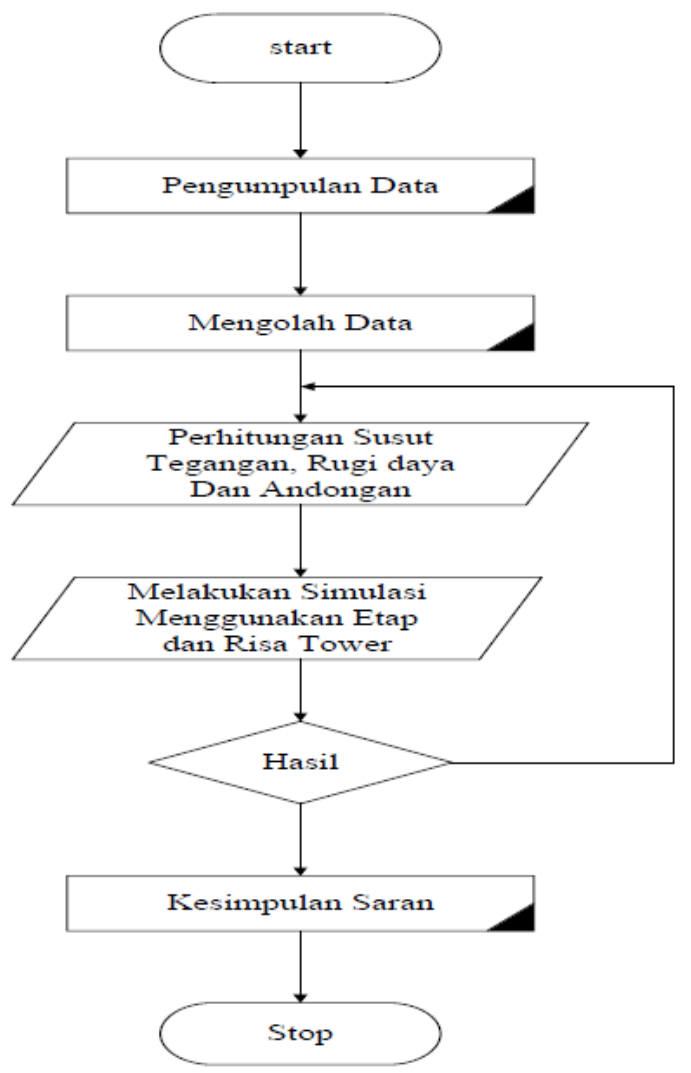

Gambar 3. Flowchart Penelitian

Dalam persamaan dapat ditulis sebagai berikut [1], [13], [14]:

$$
\begin{aligned}
& \Delta V=V_{K}-V_{T} \\
& \Delta V=I_{\text {Sal }} \times Z_{\text {Sal }}
\end{aligned}
$$

\section{Andongan Kawat Penghantar}

Konduktor yang direntangkan antara dua menara transmisi tidak akan mengikuti garis lurus. Nilai andongan (sagging) akan dipengaruhi oleh berat, jarak antara tiang (menara), temperature, dan kuat tarik konduktor yang digunakan [13]. Ada beberapa cara untuk menghitung andongan, diantaranya adalah; metode catenary, Iterasi Newton-Raphson, metode parabolik [15], [16]. Metode yang terakhir inilah yang digunakan pada artikel ini. Dengan mengacu pada Gambar 4, dimana kedua konduktor berada pada tinggi yang sama, maka Andongan (D) dapat dihitung dengan menggunakan persamaan berikut [2], [15].

$$
D=\frac{w \cdot L^{2}}{8 \cdot T_{t}}
$$

Dimana : 
$\mathrm{w}=$ Berat Konduktor

$\mathrm{L}=$ Jarak Span Rata-rata

$\mathrm{T}_{\mathrm{t}}=$ Tegangan tension konduktor

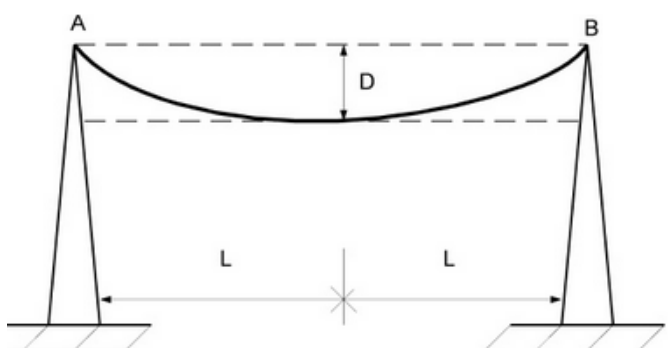

Gambar 4. Andongan Konduktor

Sebagaimana telah dijelaskan sebelumnya, bahwa temperatur akan mempengaruhi andongan kawat. Untuk menghitung andongan kawat ekonomis, yaitu andongan paling kecil pada temperatur maksimum, tetapi tegangan kawat pada keadaaan sejelek-jeleknya (yaitu pada temperatur minimum) tidak melebihi tegangan maksimum yang diizinkan. Tegangan tarik tidaklah boleh melebihi tegangan tarik yang diijinkan pada keadaan apapun. Tegangan maksimum terjadi pada saat temperatur terendah [2]

Untuk menghitung andongan akibat pengaruh temperatur dibutuhkan nilai tegangan konduktor. Dari rumus andongan diatas maka perlu ada besaran-besaran yang harus dicari terlebih dahulu untuk mendapatkan nilai andongan maksimum (D) dari data yang diketahui diatas maka dapat dicari nilai berat spesifik konduktor dengan menggunakan rumus [2]

$$
\gamma=w \cdot A
$$

Dimana :

$$
\begin{aligned}
& \gamma=\text { Berat Spesifik Konduktor } \\
& \mathrm{W}=\text { Berat Konduktor } \\
& \mathrm{A}=\text { Luas Penampang }
\end{aligned}
$$

Setelah didapat nilai berat spesifik konduktor $(\gamma)$ dan juga tegangan kerja kawat penghantar $(\sigma \mathrm{t})$ maka dapat dicari nilai andongan akibat pengaruh temperatur dengan mencari nilai luas penampang (A) menggunakan [2] :

$$
A=\frac{L^{2}+y^{2}}{24 \sigma^{2}}=E+\alpha E(t-t m)-\sigma
$$

Sementara untuk memperoleh nilai B dengan persamaan)

$$
B=\frac{L^{2} \cdot y^{2}}{24}
$$

Dimana :

$$
\begin{aligned}
\gamma & =\text { berat spesifik konduktor } \\
\sigma & =\text { tegangan konduktor spesifik } \\
\mathrm{E} & =\text { modulus elastisitas } \\
\alpha & =\text { koefisien elastisitas } \\
\mathrm{t} & =\text { temperatur } \\
\mathrm{tm} & =\text { temperatur minimum }
\end{aligned}
$$

sehingga $\sigma t 3+A \sigma t 3=B$ maka tegangan tension akibat pengaruh temperatur $T t=\sigma$ t.q.

\section{HASIL DAN PEMBAHASAN}

Impedansi Saluran $150 \mathrm{kV}$ GI Garuda Sakti - GI Balai Pungut. Panjang saluran penghantar $150 \mathrm{kV}$ dari GI Garda Sakti sampai GI Balai Pungut dengan jenis konduktor ACCC Amsterdam adalah sejauh 77,1 km dengan luas penampang konduktor $240 \mathrm{~mm}^{2}$ dan $360 \mathrm{~mm}^{2}$, maka :

$$
\begin{aligned}
Z & =77,108960(R+j X) \\
& =77,108960(0,134+\mathrm{j} 0,316) \\
& =77,108960 \times\left(0,343 \angle 67,02^{\circ}\right) \\
& =26,467 \angle 67,02^{\circ} \mathrm{Ohm} \\
& =10,33+j 24,366 \\
& =26,467 \angle 67,02^{\circ} \mathrm{Ohm} \\
Z & =77,108960(R+j X) \\
& =77,108960(0,0761+\mathrm{j} 0,220) \\
& =77,108960 \times\left(0,232 \angle 70,919^{\circ}\right) \\
& =17,889 \angle 70,919^{\circ} \mathrm{Ohm} \\
& =5,847+j 16,906 \\
& =17,95 \angle 70,919^{\circ} \mathrm{Ohm}
\end{aligned}
$$

Untuk menghitung tahanan total pada saluran $150 \mathrm{kV}$ dengan luas penampang 240 $\mathrm{mm}^{2}$ dari Garuda Sakti ke Balai Pungut adalah :

RTotal $=\mathrm{R} \times$ jarak

$$
\begin{aligned}
& =0,134 \mathrm{Ohm} \times 77,108 \mathrm{~km} \\
& =10,33 \mathrm{Ohm} / \mathrm{km}
\end{aligned}
$$

Untuk menghitung tahanan total pada saluran $150 \mathrm{kV}$ dengan luas penampang 360 $\mathrm{mm}^{2}$ dari Garuda Sakti ke Balai Pungut adalah : $\mathrm{RTotal}=\mathrm{R} \times$ jarak

$=0,0761 \mathrm{Ohm} \times 77,108 \mathrm{~km}$

$=5,867 \mathrm{Ohm} / \mathrm{km}$ 
SainETIn (Jurnal Sain, Energi, Teknologi \& Industri), Vol. 5 No. 1, Desember 2020, pp. 1 - 7

ISSN 2548-6888 print, ISSN 2548-9445 online

a. Perhitungan susut tegangan pada penghantar ACSR dengan panjang saluran 77,108960 dengan impedansi $(\mathrm{Z}) 26,466<67,02^{\circ} \Omega$ dengan luas penampang $240 \mathrm{~mm}^{2}$
$\Delta \mathrm{V}=\sqrt{3} \times \mathrm{I}$ saluran $150 \mathrm{kV} \times \mathrm{Z}$ total
$=\sqrt{ } 3 \times 164$ Amp x 26,466 Ohm
$=7.517$ Volt $=7,517 \mathrm{kV}$

Maka tegangan terima diperoleh

$$
\begin{aligned}
\mathrm{Vt} & =\mathrm{Vk}-\mathrm{Vd} \\
& =150-7,517 \\
& =142,483 \mathrm{kV}
\end{aligned}
$$

b. Perhitungan susut tegangan pada penghantar ACCC dengan panjang saluran 77,108960 dengan impedansi $(\mathrm{Z}) 17,95<70,919^{\circ} \Omega$ dengan luas penampang $360 \mathrm{~mm}^{2}$ yang terpakai pada saat ini

$$
\begin{aligned}
\Delta \mathrm{V} & =\sqrt{ } 3 \times \text { I saluran } 150 \mathrm{kV} \times \mathrm{Z} \text { total } \\
& =\sqrt{3} \times 164 \mathrm{Amp} \times 17,95 \mathrm{Ohm} \\
& =5.098 \text { Volt }=5,098 \mathrm{kV}
\end{aligned}
$$

Maka tegangan terima diperoleh

$$
\begin{aligned}
\mathrm{Vt} & =\mathrm{Vk}-\mathrm{Vd} \\
& =150-5,098 \mathrm{kV} \\
& =144,902 \mathrm{kV} \text { dengan panjang saluran }
\end{aligned}
$$

\section{0 dan $360 \mathrm{~mm}^{2}$ akibat pengaruh temperatur}

Pada perhitungan ini yang dicari adalah mencari andongan sebelum dan dilakukan pergantian pada saluran transmisi $150 \mathrm{kV}$ Garuda Sakti-Balai Pungut

$$
\text { a. } \begin{aligned}
D & =\frac{w \cdot L^{2}}{8 \cdot T_{t}}=\frac{=1,110 \times 350^{2}}{8 \times 1886,4} \\
& =9,010 \mathrm{~m} \text { (sebelum pergantian) }
\end{aligned}
$$

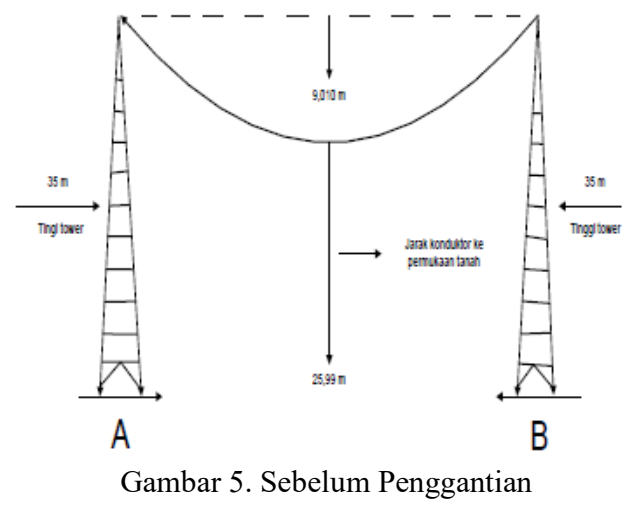

b. $\begin{aligned} D & =\frac{w \cdot L^{2}}{8 \cdot T_{t}}=\frac{1,138 \times 350^{2}}{8 \times 1402,224} \\ & =6,950 \mathrm{~m} \text { (setelah pergantian) }\end{aligned}$

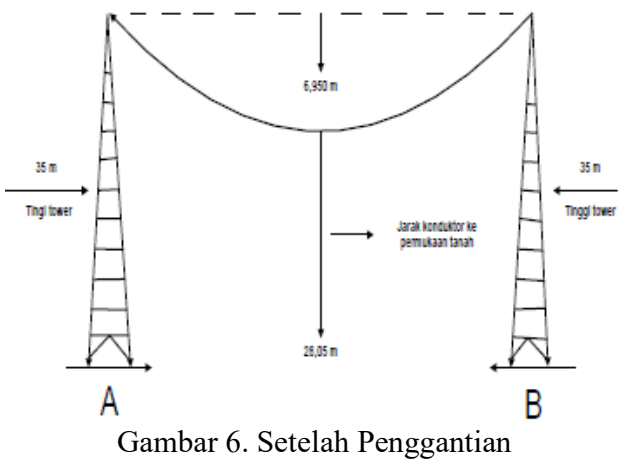

\section{KESIMPULAN}

1. Hasil perhitungan impedansi penghantar Garuda Sakti- Balai Pungut $150 \mathrm{kV}$ :

a. Pada data saluran penghantar diketahui panjang saluran penghantar GI Garuda Sakti - GI Balai Pungut (Z) sejauh $77,108960 \mathrm{~km}$ dengan luas penampang $240 \mathrm{~mm}^{2}$ (ACSR) sehingga di dapat $\mathrm{Z}$ total $26,466 \angle 67,02^{\circ} \Omega$

b. Pada data saluran penghantar diketahui panjang saluran penghantar GI Garuda Sakti - GI Balai Pungut (Z) sejauh $77,108960 \mathrm{~km}$ dengan luas penampang $360 \mathrm{~mm}^{2}$ (ACCC) sehingga di dapat Z total $17,95 \angle 70,919^{\circ} \Omega$

2. Hasil perhitungan Susut Tegangan penghantar Garuda Sakti- Balai Pungut 150 $\mathrm{kV}$ :

a. perhitungan susut tegangan pada penghantar ACSR dengan panjang saluran 77,108960 dengan impedansi $(Z)$ $26,466<67,02^{\circ} \Omega$ dengan luas penampang $240 \mathrm{~mm}^{2} 7,517 \mathrm{kV}$

b. perhitungan susut tegangan pada penghantar ACCC dengan panjang saluran 77,108960 dengan impedansi (Z) $17,95<70,919^{\circ} \Omega$ dengan luas penampang $360 \mathrm{~mm}^{2}$ yang terpakai pada saat ini adalah 5,098 kV

3. Hasil perhitungan Andongan penghantar sebelum dilakukan pergantian di Garuda Sakti-Balai Pungut $150 \mathrm{kV}$ dengan luas penampang $240 \mathrm{~mm}^{2}$ akibat pengaruh temperatur adalah 9,010 m.

4. Hasil perhitungan Andongan penghantar yang terpakai saat ini di Garuda Sakti- Balai Pungut $150 \mathrm{kV}$ dengan luas penampang 360 $\mathrm{mm}^{2}$ akibat pengaruh temperatur adalah $6,950 \mathrm{~m}$.

5. Hasil perhitungan rugi-rugi daya pada penghantar yang terpakai saat ini dengan 
luas penampang $360 \mathrm{~mm}^{2}$ ACCC pada saluran transmisi $150 \mathrm{kV}$ GI Garuda SaktiBalai Pungut adalah 23,493 kW.

6. Hasil perhitungan rugi-rugi daya pada penghantar yang terpakai saat ini dengan luas penampang $240 \mathrm{~mm}^{2}$ ACSR pada saluran transmisi $150 \mathrm{kV}$ GI Garuda SaktiBalai Pungut adalah 41,422 kW.

\section{DAFTAR PUSTAKA}

[1] C. Cekdin and T. Barlian, Transmisi Daya Listrik. Yogyakarta: Andi, 2013.

[2] T. S. Hutauruk, Transmisi Daya Listrik. Jakarta: Erlangga, 1985.

[3] A. Arismunandar and S. Kuwahara, Buku Pegangan Teknik Tenaga Listrik, Jilid II Saluran Transmisi. Jakarta: Pradnya Paramita, 2004.

[4] T. Gonen, Modern Power System Analysis, 2nd ed. Boca Raton: Taylor \& Francis, 2013.

[5] J. J. Grainer and W. D. Stevenson Jr, Power System Analysis, 5th ed. New York: McGraw-Hill, 1994.

[6] P. Gevorkian, Large-Scale Solar Power Systems: Construction and Economics. New York: Cambridge University Press, 2012.

[7] J. E. Mack, T. M. Shoemaker, and J. E. Mack, The Lineman's and Cableman's Handbook, 13th ed. New York: McGrawHill Education, 2017.
[8] I. Gunawan, H. Eteruddin, and U. Situmeang, "Analisis Transien Pada Sistem Transmisi $150 \mathrm{kV}$ Riau Setelah Beroperasinya PLTU Tenayan Raya Menggunakan Powerworld Simulator," $J$. Tek., vol. 14, no. 2, pp. 223-231, 2020.

[9] H. Eteruddin, D. Setiawan, and P. P. P. Hutagalung, "Evaluasi Jaringan Tegangan Menengah $20 \mathrm{kV}$ Pada Feeder 7 Peranap PT. PLN Persero Rayon Taluk Kuantan," in Seminar Nasional Pakar, 2020, pp. 1.4.1-1.4.6.

[10] H. Asman, H. Eteruddin, and Arlenny, "Analisis Proteksi Rele Jarak Pada Saluran Transmisi $150 \mathrm{kV}$ Garuda Sakti - Pasir Putih Menggunakan PSCAD," SainETIn, vol. 2, no. 1, pp. 27-36, 2018.

[11] A. Arismunandar, Teknik Tegangan Tinggi. Jakarta: Pradnya Paramita, 1990.

[12] Y. Chen, Engineering Energy Aluminum Conductor Composite Core (ACCC) and Its Application. London: Elsevier Science, 2019.

[13] T. Gonen, Electrical Power Transmission System Engineering: Analysis and Design, 3rd ed. Sacramento: Taylor \& Francis, 2014.

[14] T. A. Short, Electric Power Distribution Handbook, 2nd ed. Boca Raton: CRC Press, 2014.

[15] B. Wareing, Wood Pole Overhead Lines. London: IET, 2008.

[16] L. L. Grigsby, Electric Power Generation, Transmission, and Distribution, 3rd ed. CRC Press, 2012. 